\title{
Effect of AMPK signal pathway on pathogenesis of abdominal aortic aneurysms
}

\author{
Le Yang ${ }^{1}$, Lin Shen ${ }^{2}$, Peixian Gao ${ }^{1}$, Gang Li $^{1}$, Yuxiang He$^{1}$, Maohua Wang ${ }^{1}$, Hua \\ Zhou $^{1}$, Hai Yuan ${ }^{1}$, Xing Jin ${ }^{1}$ and Xuejun $\mathbf{W u}^{1}$ \\ ${ }^{1}$ Department of Vascular Surgery, Shandong Provincial Hospital affiliated to Shandong University, Jinan 250012, China \\ ${ }^{2}$ Department of Ophthalmology, Qilu Hospital of Shandong University, Jinan 250012, China \\ Correspondence to: Xuejun Wu, email: wuxuejun0704@163.com
}

Keywords: AMPK, aneurysm, inflammation, neovascularization, MMP

Received: November 18, $2016 \quad$ Accepted: August 26, $2017 \quad$ Published: October 07, 2017

Copyright: Yang et al. This is an open-access article distributed under the terms of the Creative Commons Attribution License 3.0 (CC BY 3.0), which permits unrestricted use, distribution, and reproduction in any medium, provided the original author and source are credited.

\section{ABSTRACT}

Background and aims: Determine the effect of AMPK activation and inhibition on the development of AAA (abdominal aortic aneurysm).

Methods: AAA was induced in $A p o E^{-/-}$mice by Ang II (Angiotensin II)-infusion. AICAR (5-aminoimidazole-4-carboxamide-1- $\beta$-d-ribofuranoside) was used as AMPK activator and Compound $C$ was used as AMPK inhibitor. We further investigate the effect of metformin, a widely used anti-diabetic drug which could activate AMPK signal pathway, on the pathogenesis of aneurysm.

Results: Phospho-AMPK level was significantly decreased in AAA tissue compared with control aortas. AICAR significantly reduced the incidence, severity and mortality of aneurysm in the Ang II-infusion model. AICAR also alleviated macrophage infiltration and neovascularity in Ang II infusion model at day 28. The expression of pro-inflammatory factors, angiogenic factors and the activity of MMPs were also alleviated by AICAR during AAA induction. On the other hand, Compound C treatment did not exert obvious protective effect. AMPK activation may inhibit the activation of nuclear factor-kB (NF-KB) and signal transducer and activator of transcription-3 (STAT-3) during AAA induction. Administration of metformin also activated AMPK signal pathway and retarded AAA progression in Ang II infusion model.

Conclusions: Activation of AMPK signaling pathway may inhibit the Ang IIinduced AAA in mice. Metformin may be a promising approach to the treatment of AAA.

\section{INTRODUCTION}

AAA (Abdominal Aortic Aneurysm) is the 10th leading cause of death among men over age 65 . Open surgery and endovascular repair remained to be the only two established managements of AAA [1]. These two strategies were recommended when the maximal aortic diameter was greater than $5 \mathrm{~cm}$ [2]. If these managements were not applicable, AAA will grow larger and result in rupture, with high mortality. Although many studies have been carried out to investigate the pathogenesis of AAA, effective pharmacological therapies were still not available. As a result, physicians remain incapable to modify the progression of AAA [3].
AMPK (Adenosine monophosphate-activated protein kinase) is a member of a metabolite-sensing protein kinase family, which coordinates multiple metabolic pathways to balance energy demand and supply [4]. AMPK is a trimer consisting of one catalytic subunit $(\alpha)$ and two regulatory subunits ( $\beta$ and $\gamma$ ) [5]. In mammals, each subunit has multiple isoforms and expresses in different tissues. For example, there are two isoforms ( $\alpha 1$ and $\alpha 2)$ of catabolic $\alpha$ subunit, whereas two $(\beta 1$ and $\beta 2)$ and three $(\gamma 1, \gamma 2$ and $\gamma 3)$ were present in $\beta$ and $\gamma$ subunit respectively [6]. Activation of AMPK attenuates anabolic processes such as the synthesis of proteins, fatty acids and cholesterol, and stimulates ATP (Adenosine Triphosphate) generating catabolic pathways such as respiration of glucose and fatty acids [7]. 
However, this metabolic regulatory effect of AMPK signal pathway is not the focus of this article, we dedicated to clarify the role of AMPK signal pathway in the pathogenesis of aneurysms. The activation of AMPK by metformin inhibits monocyte-macrophage differentiation and retards the pathogenesis of atherosclerosis [8]. This anti-inflammatory effect implies that AMPK activation may attenuate AAA progression considering AAA is mainly an inflammatory disease. Moreover, several recent studies reported the deletion of $\mathrm{AMPK} \alpha 1$ or AMPK $\alpha 2$ exacerbated atherosclerosis in low density lipoprotein receptor knockout mice [9, 10]. However, according to another investigation, AMPK $\alpha 2$ activation by nicotine instigates formation of aneurysms in the Ang II (Angiotensin II) infusion model. In that study, AMPK $\alpha 2$ ${ }^{-} \mathrm{ApoE}^{-/-}$mice is resistant to aneurysmal formation [11]. These controversial results make it difficult to illuminate the relationship between pharmacological activation/ inhibition of AMPK signal pathways and prognosis of AAA.

Ang II infusion model, a widely accepted mice model of aneurysm, [12] was adopted in this investigation. Two in vivo experiments were designed to evaluate the relationship between pharmacological activation/ inhibition of AMPK and formation of AAA. AICAR (5-aminoimidazole-4-carboxamide-1- $\beta$-d-ribofuranoside) was used as AMPK activator and Compound $\mathrm{C}$ was used as AMPK inhibitor in the first in vivo study. Results of this study indicated AMPK activation may be beneficial to the prevention of AAA. Based on this, metformin, the most widely used anti-diabetic drug which had been reported to activate AMPK signal pathway, [13] was used in the second in vivo study to evaluate its pharmacological effects in AAA progression. Our results indicated AMPK activation could retard AAA progression and metformin may be used as a promising approach to the treatment of AAAs.

\section{RESULTS}

\section{Decreased phospho-AMPKa levels and

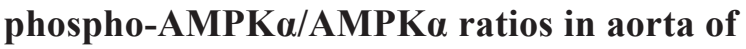 AAA patients}

The baseline clinical characteristics, diameter of aneurysm, and regular use of medication of the AAA patients were presented in the Supplementary Table 2. We firstly examined levels of phospho-AMPK $\alpha$ and total AMPK $\alpha$ in AAA tissues and control aortic tissues. Western blot analysis showed that there were no significant difference in total AMPK $\alpha$ protein levels between control aortic tissues and AAA tissues. On the other hand, phosphoAMPK $\alpha$ level was significantly lower in AAA tissues than in control aortic tissues, indicating the reduced activation of AMPK $\alpha$ signal pathway in human AAA. (Figure 1A-1B) The expression of phospho-AMPK $\alpha$ was readily detectable in the media of control aorta, whereas it was barely detectable in the AAA tissues. (Supplementary Figure 1)

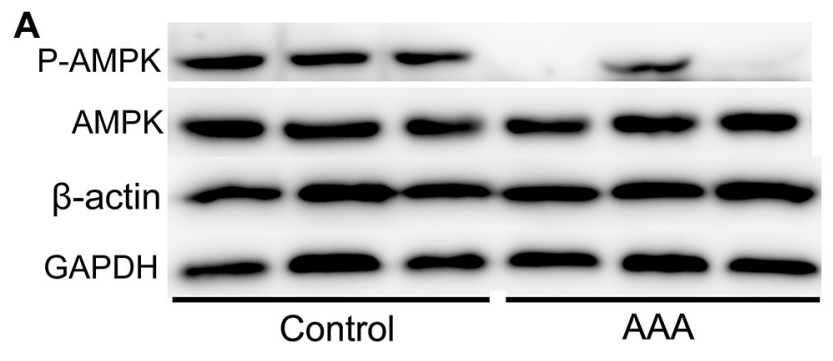

B

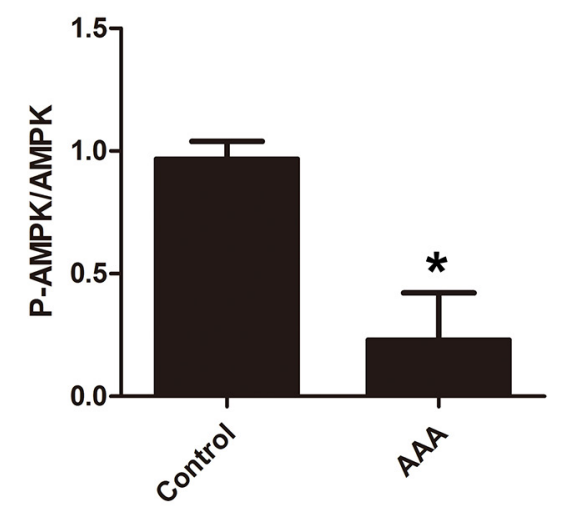

Figure 1: Decreased phospho-AMPK levels in the aortic wall of human abdominal aortic aneurysm (AAA) tissues. (AB). Protein expression of P-AMPK, AMPK, $\beta$-actin and GAPDH of aneurysmal tissue and control aortic wall. Results are means \pm S.E.M. ( $n=15$ in AAA group, $n=8$ in control group). ${ }^{*} P<0.05$ vs. Control group. 


\section{Effect of AMPK signal pathway on the incidence of AAA in Ang II induced AAAs}

Ang II infusion elevated the HR (heart rate) and BP (blood pressure) of mice modestly, while compound $\mathrm{C}$ and AICAR had no significant effect on the BM (body mass), HR, and BP (Supplementary Table 3). Maximal aortic diameters were increased in $\mathrm{AAA}, \mathrm{AAA}+\mathrm{C}$. C (AAA+compound $\mathrm{C}$ ) and AAA+AICAR groups. The aneurysmal incidence, severity and mortality were significantly lower in AAA+AICAR group compared with AAA group. On the other hand, the maximal aortic diameter in AAA + C. $C$ group was slightly larger than AAA group. (Figure 2A-2B, 2D)

\section{Effect of AMPK signal pathway on Ang II induced morphological and histological changes in $\mathrm{ApoE}^{-/-}$mouse aortas}

HE staining revealed destruction of the media and thickening of the adventitia in the AAA group compared with the sham group. These pathological features were aggravated in the AAA+C. $\mathrm{C}$ group and alleviated in the AAA+AICAR group. (Figure 2C) The relative contents of collagen and SMCs in the aortic wall were substantially increased in the AAA+AICAR group, whereas the content of macrophages and microvessels was decreased in the AAA+AICAR group. In contrast, these parameters showed only insignificant difference between the AAA group and $\mathrm{AAA}+\mathrm{C}$. C group. (Figure 3A-3E) Immunohistochemistry after polyclone antibodies pre-absorption with relative full-length antigens diminishes their labelling in mice aneurysmal tissue sections. (Supplementary Figure 2A2C) The goat-anti-mouse negative control showed little positive staining area in all groups. (Supplementary Figure $3 \mathrm{~A})$

\section{Effect of AMPK signal pathway on the expression of proinflammatory cytokines, vascular growth cytokines and the activity of metal matrix proteinase}

As chronic inflammation of the aortic wall is a main feature of AAA, we examined the expression of proinflammatory cytokines, such as IL (interleukin)-1 $\beta$, IL-6, MCP (monocyte chemotactic protein)-1 and TNF (tumor necrosis factor)- $\alpha$. Expression of these cytokines in the AAA+AICAR group was significantly lower than those in the AAA group. While in the AAA+C. C group, expression of those proinflammatory cytokines was slightly higher. (Figure 4A) Neovascularization is also of vital importance in the AAA progression. VEGFA (vascular endothelial growth factor A), Flt (fms related tyrosine kinase)-1 and CD31(cluster of differentiation31) are the major vascular growth factors in the AAA progression. PCR analysis revealed the expression of

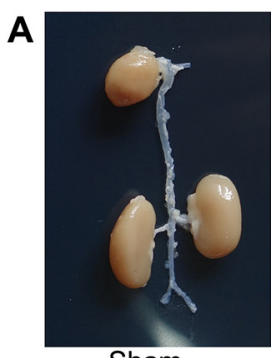

Sham

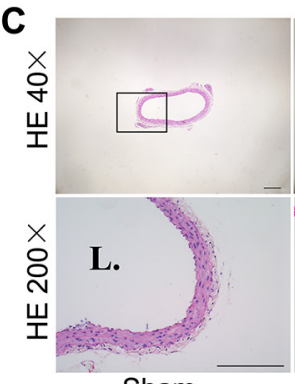

Sham

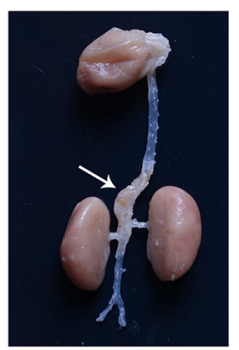

AAA

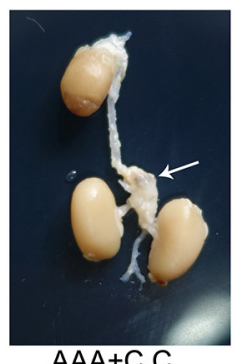

$\mathrm{AAA}+\mathrm{C} . \mathrm{C}$

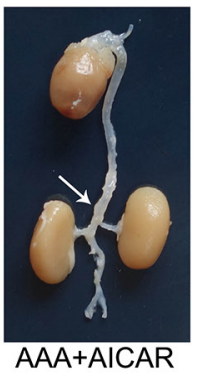

AAA+AICAR

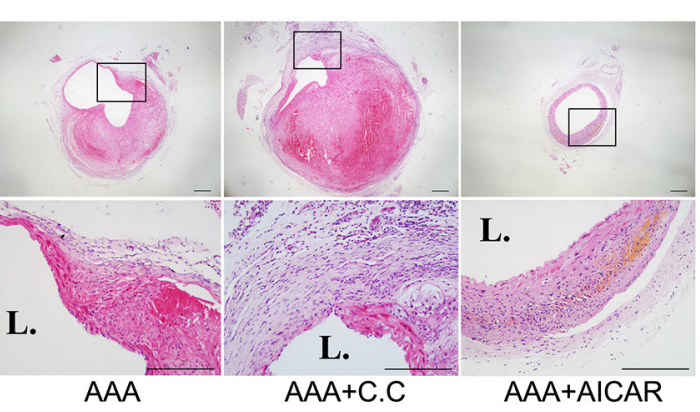

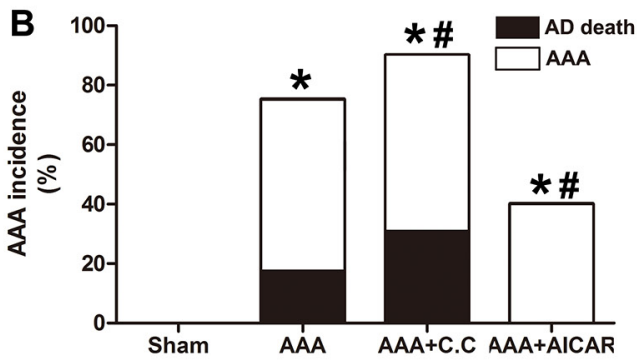

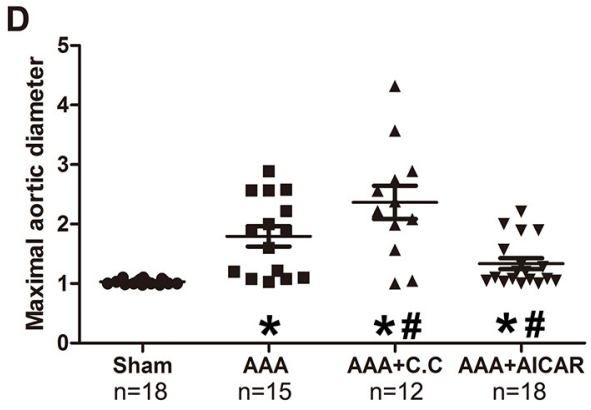

Figure 2: The activation of AMPK signal pathway retarded AAA progression while inhibition of AMPK signal pathway tended to aggravate AAA progression. (A). Representative macroscopic appearance of the aorta in 4 groups of mice who received treatment with PBS (sham group), Ang II (AAA group), Ang II plus Compound C (AAA+C.C group), Ang II plus AICAR (AAA+AICAR group), respectively. This figure is a representative figure of survival mice ( $\mathrm{n}=18$ in sham group, $\mathrm{n}=15$ in AAA group, $\mathrm{n}=12$ in AAA $+\mathrm{C}$. $\mathrm{C}$ group, $\mathrm{n}=18$ in AAA+AICAR group). The arrow indicated aneurysmal portion of each group. (B) Incidence and mortality of AAA in 4 groups of mice. (C) Representative hematoxylin and eosin staining in 4 groups of mice. (D) Maximal abdominal aortic diameters in all survival mice of 4 groups of mice. Scale bar indicated $200 \mu \mathrm{m}$. Results are means \pm S.E.M. ${ }^{*} \mathrm{P}<0.05$ vs. Sham group; ${ }^{\# P}<0.05$ vs. AAA group. 
these cytokines were elevated after AAA induction and this elevation could be attenuated by AICAR.(Figure 4B) IHC staining showed a reduced MMP-2 and MMP9 positive area in AAA+AICAR group compared with AAA group (Supplementary Figure 3B-3C). The abundance of zymographic active form of MMP-2 and MMP-9 was increased in AAA group compared with Sham group. The activity of MMP-2 and MMP-9 were attenuated by AICAR. (Figure 4C-4D) PCR analysis also showed a reduced MMP-2 and MMP-9 mRNA level in AAA+AICAR group compared with AAA group. (Figure $4 \mathrm{E}$ ) Compound $\mathrm{C}$, on the other hand, aggravated the expression and activity of MMPs in AAA mice.

\section{STAT-3 and NF- $\mathrm{KB}$ signaling were involved in the effect of AMPK signal pathway on Ang II- induced AAA}

To verify the signaling proteins, we examined the expression level of AMPK, STAT-3 and NF- $\kappa$ B signal pathway. In AAA mice, Phospho-AMPK production was significantly decreased while NF- $\kappa \mathrm{B}$ and PhosphoSTAT-3 were increased compared with the sham group mice. AICAR group activate AMPK phosphorylation in AAA mice. AAA+AICAR group showed a lower level of Phospho-STAT-3 and NF- $\kappa$ B expression compared with AAA group. (Figure 5A-5E) $\mathrm{AAA}+\mathrm{C}$. C group downregulate AMPK phosphorylation while upregulate the NF- $\kappa$ B expression and STAT-3 phosphorylation. (Figure 5A-5E) In conclusion, there may be a causal reciprocal relationship between AMPK signal pathway

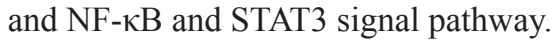

\section{Metformin downregulate on the incidence of AAA in Ang II infused mice}

Metformin, a widely used anti-diabetic drug which could activate AMPK signal pathway in vivo, was further evaluated in this study. Metformin $(300 \mathrm{mg} / \mathrm{kg}$ in daily drinking water) reduced the incidence, severity and mortality of AAA. (Figure 6A-6B, 6D) Absolute aortic growth was significantly less in metformin treated mice.
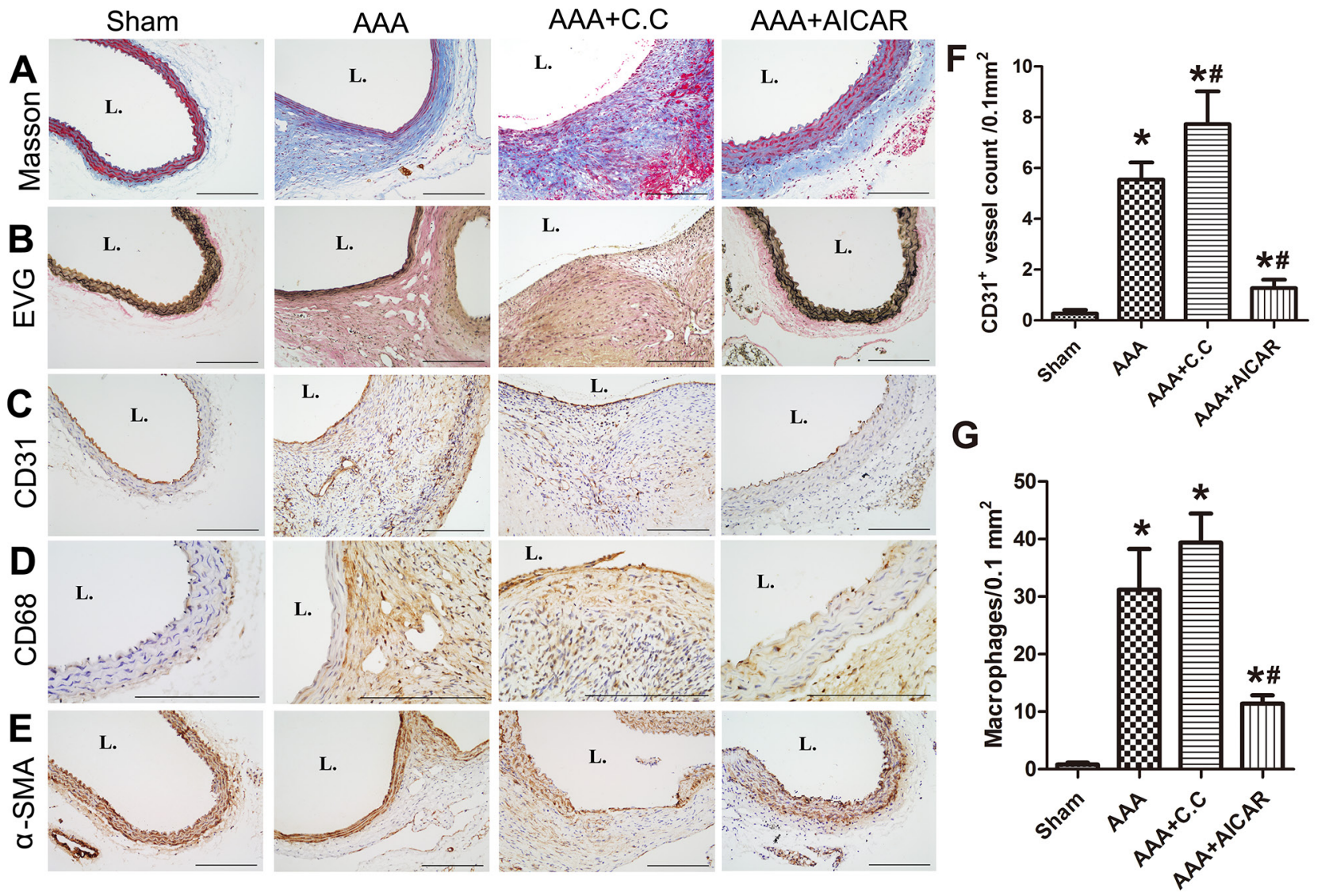

Figure 3: AMPK activation alleviated pathological features of AAA. (A-B) Representative photomicrographs of Masson trichrome staining, elastic Van Gieson (EVG) staining of 4 groups of mice. ( $\mathrm{n}=5$ in each group used in pathological experiment) (C-E) Representative photomicrographs of CD31, CD68, $\alpha$-SMA, staining of abdominal aortas of 4 groups of mice. Scale bar indicated $200 \mu \mathrm{m}$. (F-G) Quantitative analysis of CD31 positive vessels and CD68 positive cells in different groups. Results are means \pm S.E.M. ${ }^{*} \mathrm{P}<0.05$ vs. Sham group; ${ }^{\mathrm{P}}<0.05$ vs. AAA group. 


\section{Effect of metformin on ang II induced morphological} and histological changes in $\mathrm{ApoE}^{-/-}$mouse aortas

Metformin reduced the destruction of media and the marked thickening of adventitia. (Figure 6C) Metformin treatment also preserved the collagen and SMCs in the wall of aneurysm. On the other hand, macrophages and microvessels in the aneurysmal wall were reduced in the metformin treatment group. (Figure 7A-7E)

Metformin downregulates the expression of proinflammatory cytokines, vascular growth cytokines and the activity of metal matrix proteinase

Compared with the AAA group, metformin inhibited the expression of proinflammatory cytokines such as IL$1 \beta$, IL-6, MCP-1 and TNF- $\alpha$. (Figure 8A) Administration of metformin also inhibited the expression of vascular growth cytokines such as VEGFA, Flt-1 and CD31. (Figure 8B) Gelatin zymography analysis revealed reduced MMP-2 and MMP-9 activity after metformin treatment. (Figure 8C-8D) PCR analysis also showed a reduced MMP-2 and MMP-9 mRNA level in AAA+MET group compared with AAA group. (Figure 8E) IHC staining showed a reduced MMP-2 and MMP-9 positive area in AAA+MET group compared with AAA group (Supplementary Figure 4A-4B).

STAT-3 signaling and NF- $\mathrm{KB}$ signaling were involved in the effect of metformin on Ang II-induced AAA

In AAA mice, Phospho-AMPK production was significantly decreased while NF- $\mathrm{kB}$ and phospho-STAT-3 were increased compared with the sham group mice.

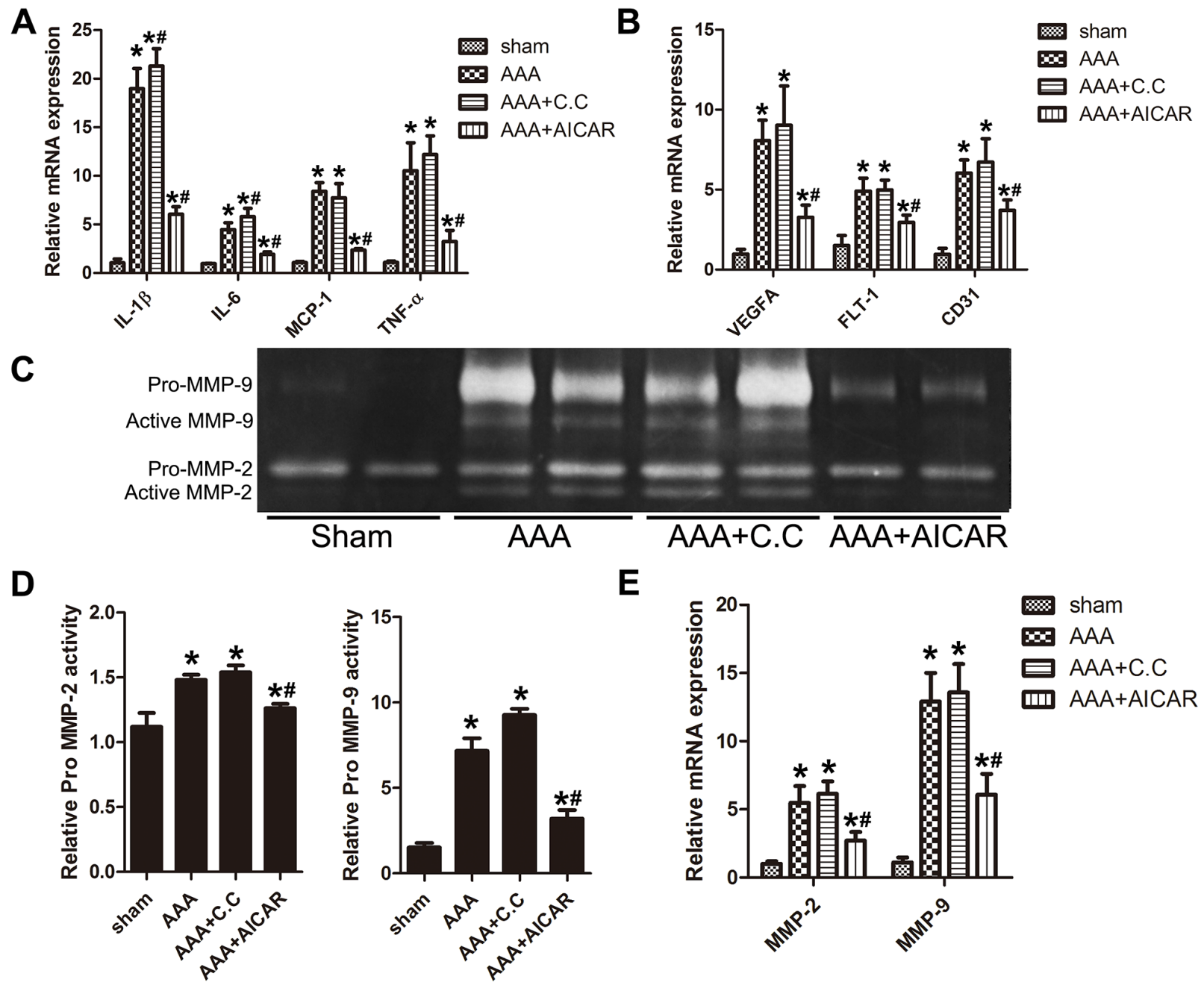

Figure 4: Quantitative RT-PCR analysis, gelatin zymography analysis of different groups of mice. (A) Expression of IL$1 \beta$, IL-6, MCP-1 and TNF- $\alpha$ in abdominal aorta of 4 groups of mice. (B) Expression of VEGFA, Flt-1 and CD31 in abdominal aortas of 4 groups of mice. (C) Gelatin zymography of MMP-2 and MMP-9 activity and their quantitative analysis (D). (E) Expression of MMP-2 and MMP-9 in abdominal aortas of 4 groups of mice. Results are means \pm S.E.M. ( $n=5$ in each group) ${ }^{*} \mathrm{P}<0.05$ vs. Sham group; ${ }^{*} \mathrm{P}<0.05$ vs. AAA group. 
(Figure 9A-9E) Metformin treatment activated AMPK phosphorylation in AAA mice. After metformin treatment, the NF- $\kappa$ B expression and STAT-3 phosphorylation were downregulated. (Figure 9A-9E).

\section{DISCUSSION}

To the best of our knowledge, this is the first study in the literature to report the pharmacological activation/ inhibition of AMPK signal pathway and pathogenesis of abdominal aortic aneurysm. Human tissue study suggested that AMPK signal pathway seems to be inhibited in AAA patients. The in vivo study demonstrated that activation of AMPK signal pathway by AICAR reduced the incidence, severity and mortality of aneurysm, while the inhibition of AMPK signal pathway by Compound $\mathrm{C}$ tended to aggravate AAA progression. Activation of AMPK signal pathway seems to be associated with the inhibited NF- $\kappa B$ and STAT-3 signal pathway, which are of vital importance in the chronic inflammation in the AAA progression. Moreover, we illustrated that metformin, which had proven to be an AMPK activator, significantly attenuated Ang II-induced aortic aneurysm in $\mathrm{ApoE}^{-/-}$mice. These results indicated that metformin could be a potential pharmacological therapy in AAA.

All three major cell types (endothelial cells, VSMC, and monocytes/macrophages) in the vasculature express AMPK $\alpha$. AMPK $\alpha 1$ is the major isoform in vasculature cells is where as AMPK $\alpha 2$ is the minor isoform [10]. Previous studies illustrated AMPK signal pathway ( $\alpha 1$ and $\alpha 2)$ confers protection to various cardiovascular diseases, such as atherosclerosis, atherosclerotic vulnerability and atherosclerotic calcification [9, 10, 14]. Another study reported AMPK $\alpha 2$ could be activated by nicotine and initiate MMP-2 secretion in VSMCs. On the other hand, AMPK $\alpha 2$ knockout confers protection to AAA formation [11]. These controversial reports make it difficult to evaluate AMPK signal pathway in the development of aneurysm. We firstly observed significantly reduced levels of Phosphate-AMPK $\alpha$ in human AAA tissues than in control aortas. This clinical tissue investigation indicated that impairment of AMPK signal pathway may

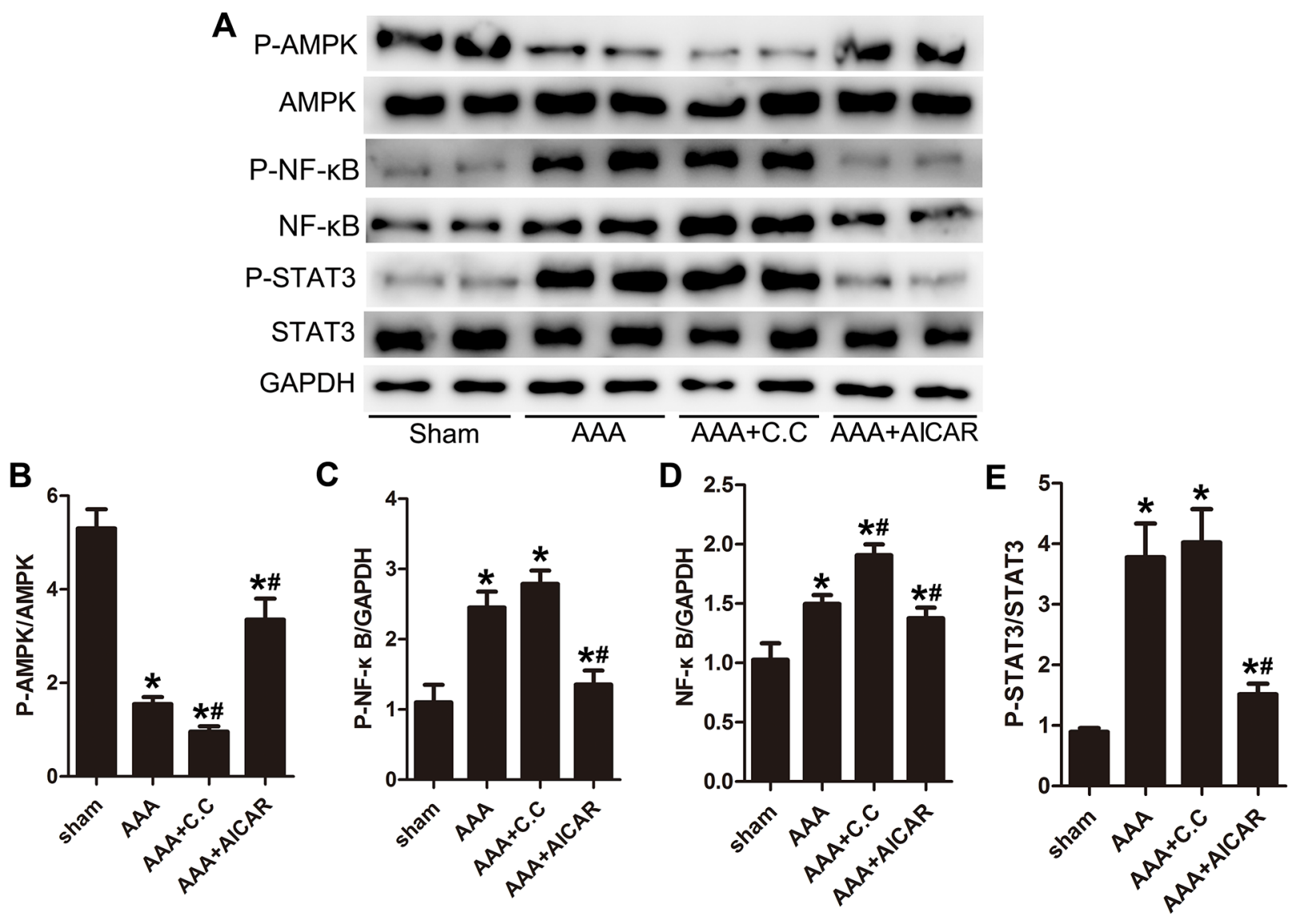

Figure 5: AMPK signal pathway correlated with NF- $\mathrm{B}$ and STAT-3 signal pathways during AAA progression. (A), Representative Western blot analysis of phospho-AMPK (P-AMPK), AMPK, phospho-nuclear factor- $\kappa \mathrm{B}$ (P-NF- $\kappa \mathrm{B}), \mathrm{NF}-\kappa \mathrm{B}, \mathrm{phospho-}$ STAT3 and STAT3 in abdominal aortas of 4 groups of mice. (B-C) Quantitative analysis of P-AMPK normalized to AMPK protein level and P-NF- $\kappa$ B expression normalized to GAPDH level. (D-E) Quantitative analysis of NF- $\kappa$ B normalized to GAPDH level and P-STAT3 expression normalized to STAT3 level. Results are means \pm S.E.M. $\left(n=5\right.$ in each group ${ }^{*} \mathrm{P}<0.05$ vs. Sham group; ${ }^{*} \mathrm{P}<0.05$ vs. AAA group. 
promote AAA formation. However, whether the activation of AMPK signal pathway exerts the protective effect on AAA formation remain elusive.

Although different isoforms of AMPK $\alpha$ could be evaluated by genetic editing method, pharmacological activation or inhibition of different AMPK $\alpha$ isoform remains impossible [15, 16]. Moreover, the strong homology between the AMPK $\alpha 1$ and AMPK $\alpha 2$ sequences in the vicinity of the substrate binding groove, suggests that the substrate specificities will be related [5]. Considering previously controversial results on the relationship between AMPK signal pathway and the formation of AAA, further studies of AMPK signal pathway in the aneurysm are needed to be carried out. In the first in vivo experiment, AICAR was used as AMPK activator and Compound $\mathrm{C}$ was used as AMPK inhibitor. AICAR is converted to 5-aminoimidazole-4-carboxamide ribonucleoside (ZMP) in the cell where it mimics AMP binding to AMPK increases its phosphorylation at threonine 172, leading to prolonged activation of AMPK signal pathway $[17,18]$. Compound $\mathrm{C}$, on the other hand, is widely used in the in vitro and in vivo assays as a selective AMPK inhibitor [19]. It is worth mention that AICAR or compound $\mathrm{C}$ might have effects on signaling pathways other than AMPK; $[17,20,21]$ however, there are no known enzymatic pathways that are both stimulated by AICAR and inhibited by compound C, [6,
22] suggesting that the effects of AICAR or compound $C$ were due to AMPK signal pathway.

Infiltration of macrophages, neovascularization and elastic degradation are the main pathological features of aneurysm [23, 24]. These three pathological changes are interdependent and of vital importance in the formation and progression of AAAs. Macrophages themselves secrete MMPs and VEGFs to promote neovascularization and elastic degradation $[25,26]$. On the other hand, neovascularization and elastic degradation can facilitate macrophage's infiltration into the AAA portion [27, 28]. Several previous studies had reported that the activation of AMPK signal pathway could exert antiinflammatory and anti-neovascularization effect in atherosclerosis, cancer and chronic kidney disease [9, 29, 30]. In this study, activation of AMPK signal pathway, markedly reduced macrophage accumulation in AAA tissues and significantly decreased the expression of proinflammatory cytokines, such as MCP-1, IL-1 $\beta$, IL-6 and TNF- $\alpha$. On the other hand, inhibition of AMPK signal pathway does not exert such beneficial effects. Moreover, AMPK activation also reduced the mural microvessels density and the expression of several angiogenic factors such as VEGFA, CD31 and Flt-1. These results indicate activation of AMPK may alleviate chronic inflammation and neovascularization in AAA tissue.
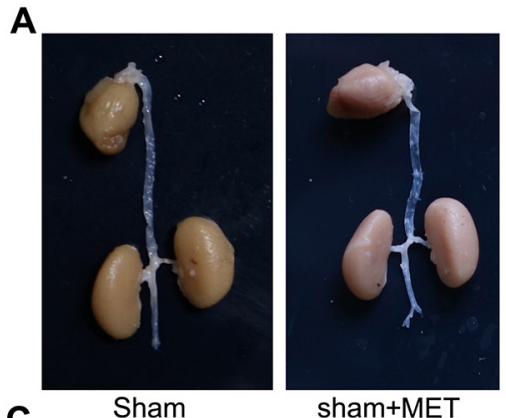

sham+MET
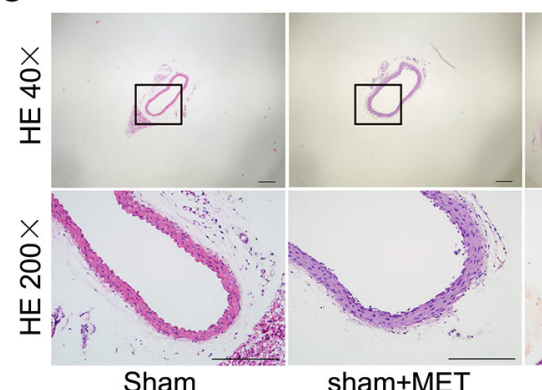

sham+MET

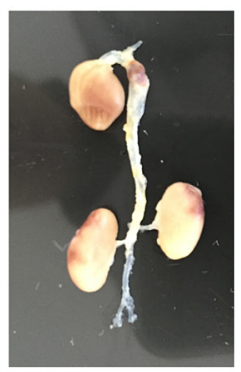

AAA

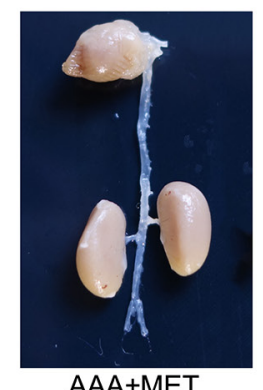

$\mathrm{AAA}+\mathrm{MET}$

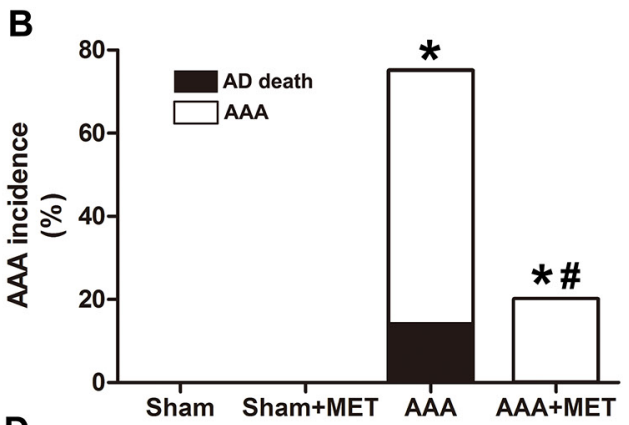

D

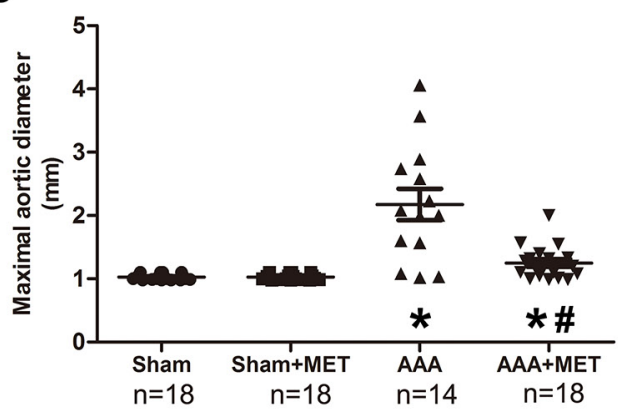

Figure 6: Orally administration of metformin retarded AAA progression in Ang II infusion model. (A). Representative macroscopic appearance of the aorta in 4 groups of mice who received treatment with PBS, Metformin (MET), Ang II, Ang II plus metformin, respectively. This figure is a representative figure of survival mice ( $\mathrm{n}=18$ in sham group, $\mathrm{n}=18$ in Sham+MET group, $n=14$ in AAA group, $n=18$ in AAA+MET group). (B) Incidence and mortality of AAA in 4 groups of mice. (C) Representative hematoxylin and eosin staining in 4 groups of mice. (D) Maximal abdominal aortic diameters in 4 groups of mice. Scale bar indicated $200 \mu \mathrm{m}$. Datas are means \pm S.E.M. ${ }^{*} \mathrm{P}<0.05$ vs Sham group; ${ }^{\#} \mathrm{P}<0.05$ vs AAA group. 
Several articles had discussed the possible molecular mechanisms underlying the relationship between the activity of AMPK signal pathway and the chronic inflammation in the macrophages, which is the main pathological feature in AAA. AMPK was first implicated in chronic inflammation in studies showing that AMPK activators diminish inducible iNOS (inducible nitric oxide synthases) synthesis in macrophages and adipocytes. [31] Subsequently, Sag et al. [32] reported that treatment of macrophages with anti-inflammatory cytokines, such as IL-10 and TGF- $\beta$, rapidly activated AMPK in these cells, whereas the proinflammatory stimulus LPS diminished AMPK activity. Likewise, inhibition of AMPK activity by RNAi (RNA interference) or transfection of an inactive AMPK mutant enhanced LPS-induced increases in the inflammatory cytokines TNF- $\alpha$ and IL- 6 and diminished IL-10 in these cells. More recently, Yang and coworkers [33] demonstrated that increased AMPK activity, caused by the expression of a constitutively active AMPK $\alpha 1$, inhibits both LPS and palmitate-induced NF- $\mathrm{KB}$ signaling in macrophages. They also observed that inactivating AMPK in macrophages in a macrophage/adipocyte co-culture system inhibited both insulin signaling and glucose uptake in the adipocytes (i.e., it produced ischemia reperfusion injury). Finally, the same investigators found that AMPK activation increased SIRT1 (Sirtuin 1) expression in macrophages and that this led to the deacetylation and downregulation of NF- $\mathrm{KB}$ (i.e., decreased inflammation).

MMP-2 and MMP-9 work in concert to produce aortic aneurysms [34]. Previously study revealed that the activation of AMPK $\alpha 2$ by nicotine could initiate MMP2 secretion in VSMC to induced AAA in $\mathrm{ApoE}^{-/-}$mice [11]. However, another study reported AMPK $\alpha 2$ deletion could induce plaque instability in $\mathrm{ApoE}^{-/}$mice [10]. In our study, MMP-2 activity does not alter significantly after AMPK $\alpha$ activation. There was a significantly reduced MMP-9 activity after the use of AMPK activators. The reduced MMP-9 activity may be associated with reduced aortic mural macrophage infiltration considering macrophages are the major sources of MMP-9 [34]. Besides this, previous studies reported AMPK activator may exert a direct prohibitive effect on MMP-9 secretion. The activation of AMPK $\alpha$ by metformin or other anti-oxidant agents can inhibit MMP-9 secretion in macrophages [8].

NF- $\kappa$ B and STAT- 3 are the key proinflammatory transcription factors responsible for the regulation of the cytokine network in vasculature cells $[35,36]$. Angiotensin

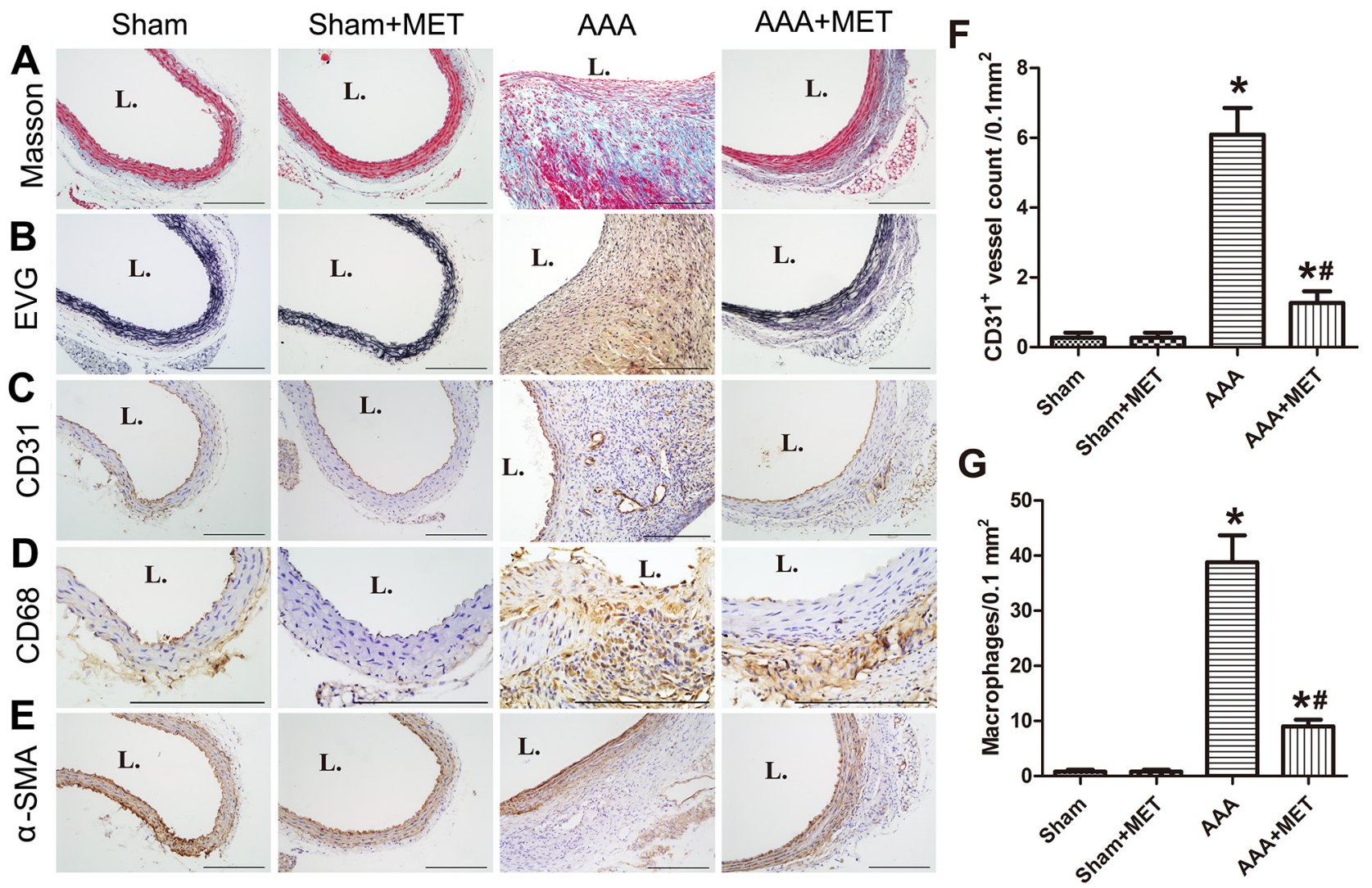

Figure 7: Orally administration of metformin alleviated pathological features of AAA. (A-B) Representative photomicrographs of Masson trichrome, elastic Van Gieson (EVG) ( $\mathrm{n}=5$ in each group used for histological experiment), (C-E) Representative photomicrographs of CD31, CD68, $\alpha$-SMA staining of abdominal aortas of 4 groups of mice. Scale bar indicated $200 \mu \mathrm{m}$. (F-G) Quantitative analysis of CD31 positive vessels and CD 68 positive cells in 4 groups of mice. Results are means \pm S.E.M. ${ }^{*}<0.05$ vs. Sham group; ${ }^{*} \mathrm{P}<0.05$ vs. AAA group. 
II and other aneurysmal prone factors (such as nicotine and etc.) may activate NF- $\kappa \mathrm{B}$ in smooth muscle cells and macrophages, which in turn promotes AAA development. The activities of NF- $\mathrm{B}$ and STAT-3 also correlated with AAA severity [37]. STAT3 activation is necessary for Ang II-stimulated MMP secretion and the increase in total macrophages and the ratio of $\mathrm{M} 1 / \mathrm{M} 2$ macrophages in suprarenal aortas of ApoE $\mathrm{E}^{-/-}$mice $[8,35]$. In the present study, NF- $\kappa$ B and STAT-3 activation was significantly attenuated in AICAR group, suggesting that the effect of AMPK activation in AAA model was correlated with downregulating NF- $\kappa$ B and STAT-3 activation. However, because of the limited mice aortic tissue in each group, images of P-NF- $\kappa$ B and P-STAT3 for Sham and AAA in Figure 5A are quite inconsistent in those in Figure 9A.
Another important finding in this study is orally administration of metformin could delay the formation of aneurysm. Metformin, as the most commonly used antidiabetic agents, has beneficial effects in cardiovascular complications besides glycemic control [8]. Earlier studies had shown that the pleiotropic benefits of metformin are in part mediated by the activation of AMPK [38]. Metformin had been proven to improve the lifespan and healthy span in mice via AMPK signal pathway [39]. Previous studies showed metformin could effectively inhibit PMAinduced monocyte-to-macrophage differentiation through the activation of AMPK $\alpha$ [8]. Another article reported metformin to suppress the enlargement of aneurysm in AAA patients [40]. Our experiment revealed metformin could suppress Ang-induced aneurysm progression,
A

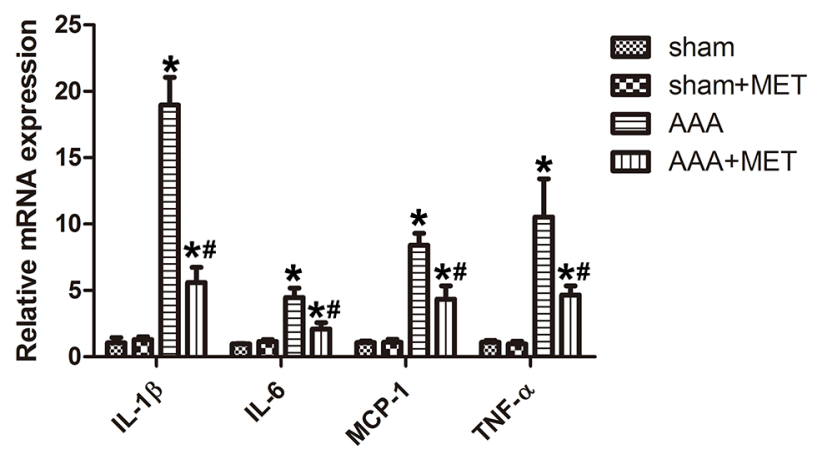

B

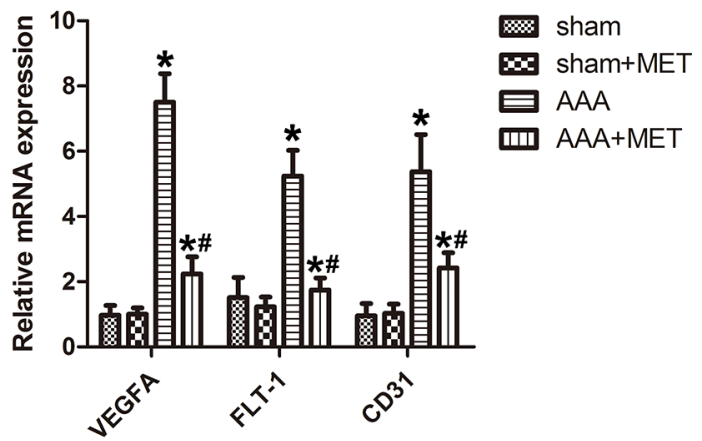

C

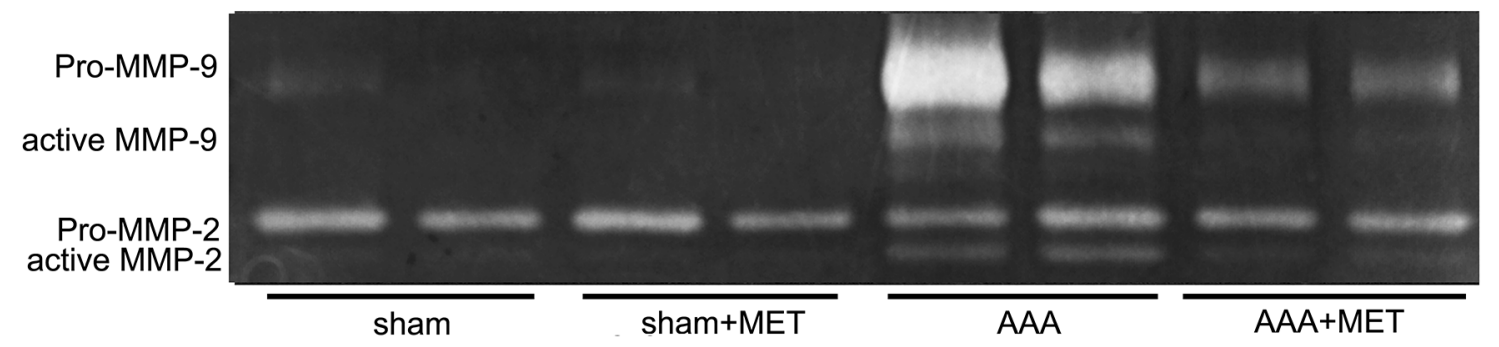

D

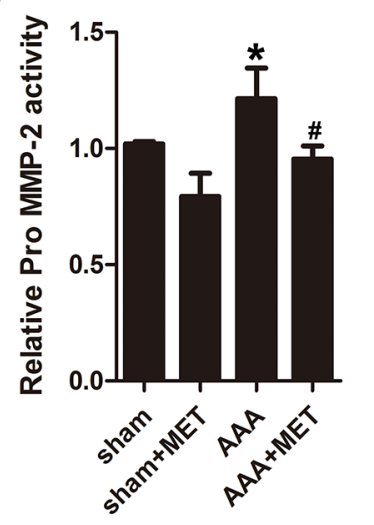

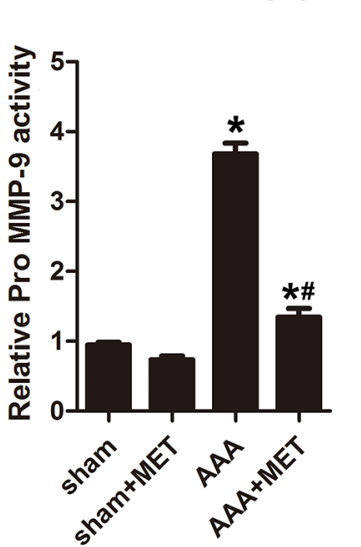

E

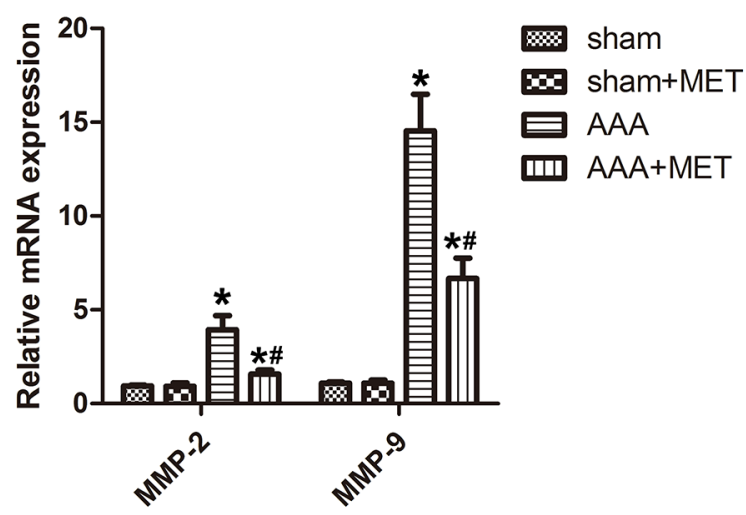

Figure 8: Quantitative RT-PCR analysis, gelatin zymography analysis of different groups of mice. (A) Expression of IL$1 \beta$, IL-6, MCP-1 and TNF- $\alpha$ in abdominal aortas of 4 groups of mice. (B) Expression of VEGFA, Flt-1 and CD31 in abdominal aortas of 4 groups of mice. (C) Gelatin zymography of MMP-2 and MMP-9 activity and their quantitative analysis (D). (E) Expression of MMP-2 and MMP-9 in abdominal aortas of 4 groups of mice. Results are means \pm S.E.M. ( $n=5$ in each group) ${ }^{*} \mathrm{P}<0.05$ vs. Sham group; ${ }^{*} \mathrm{P}<0.05$ vs. AAA group. 
possibly by the activation of AMPK signal pathway. These results indicated that metformin may serve as an effective and safe drug to control AAA progression.

There were several limitations in this investigation. Firstly, all drugs including ACIAR [41, 42], Compound $\mathrm{C}[20,42]$ and metformin [43] have off-target effects. Through this investigation, we can only delineate a potential link between the AMPK activation and the retard of aneurysmal growth. Genetic investigation may be beneficial to set aside the off-target effect of these chemical compounds. However, by using genetic approach, scientists can only evaluate role of AMPK $\alpha 1$ or AMPK $\alpha 2$ in the pathogenesis of aneurysm separately. Considering this, using chemical compound may be indispensible to evaluate the overall effect of AMPK signal pathway on the pathogenesis of aneurysms. Secondly, the in vitro study (cell experiment) was not included in this study. Many different types of cells, such as smooth muscle cells, [44] macrophages, [8] mast cells [45] and even perivascular adipose tissue [46] were involved in the development of aneurysm. The in vitro study using a specific cell type may be not sufficient to explain the overall mechanism of one drug in the development of aneurysm.

\section{MATERIALS AND METHODS}

\section{Patients enrollment and tissue collection}

Patients with aortitis, connective tissue disorders, or ruptured aneurysm were excluded. During surgery, aortic tissues were collected from the largest portion of the aneurysm, which were routinely excised and discarded during repair. Control abdominal aortic tissue was collected from 8 age-matched organ donors without aortic aneurysm, dissection, coarctation or previous aortic repair. Periaortic fat and intraluminal thrombus were trimmed away, and samples were rinsed with PBS. Samples were snap frozen and stored at $-80^{\circ} \mathrm{C}$ for protein analysis. This study was approved by the Medical Ethics Committee of Shandong Provincial Hospital affiliated to Shandong
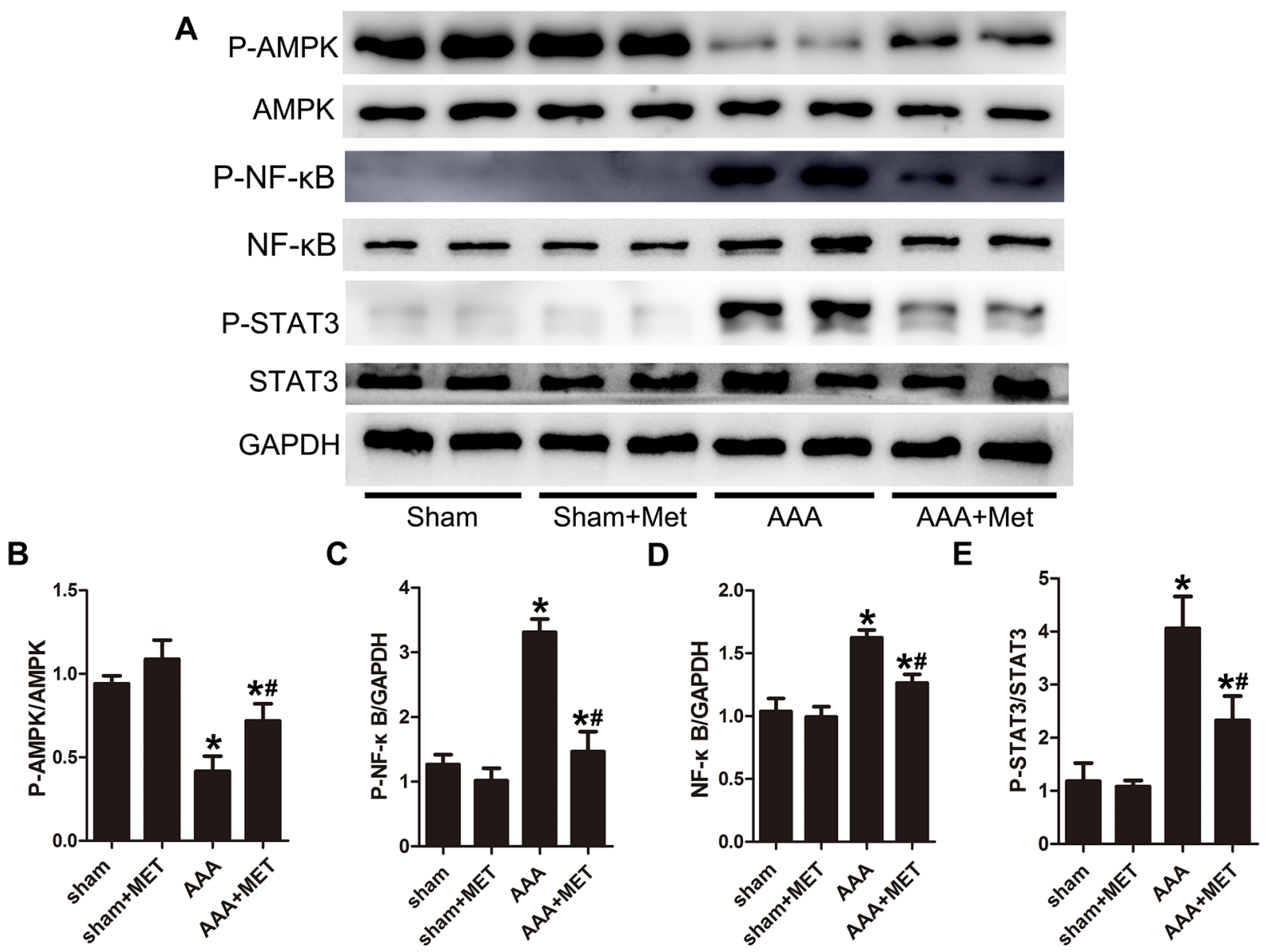

Figure 9: Metformin decreased the activity of NF-кB and STAT-3 signal pathway during AAA progression. (A),

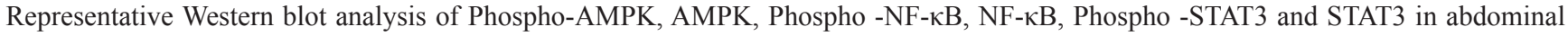
aortas of 4 groups of mice. (B-C) Quantitative analysis of Phospho -AMPK normalized to AMPK protein level and Phospho -NF- $\kappa B$ expression normalized to GAPDH level. (D-E) Quantitative analysis of NF- $\kappa B$ normalized to GAPDH level and P-STAT3 expression normalized to STAT3 level. Results are means \pm S.E.M. ( $n=5$ in each group) ${ }^{*} \mathrm{P}<0.05$ vs. Sham group; ${ }^{*} \mathrm{P}<0.05$ vs. AAA group. 
University and was conducted in accordance with the Declaration of Helsinki. Informed consent was obtained from all participants.

\section{AAA model}

The AAA model was induced in $\mathrm{ApoE}^{-/}$ (apolipoprotein E deficient) mice (C57B16/J background) at the age of 8 to 10 weeks as described previously. Briefly, mice were implanted with Alzet osmotic minipumps (Model 1004, Durect Corporation), filled with Ang II solutions (Abcam, Cambridge, United Kingdom. Ab120183, 1,000 ng/kg/min) under anesthesia by intraperitoneal injection of chloralhydrate $(30 \mathrm{mg} /$ $\mathrm{kg}$ of body mass). The infusion persisted for up to 4 weeks. At indicated time point, mice were sacrificed for image acquisition and tissue harvest. All procedures were approved by the Animal Care and Use Committee of Shandong Provincial Hospital and were conducted following the institutional guidelines.

\section{Treatment with AMPK modulators in AAA model}

Two in vivo experiments were designed to evaluate the relationship between pharmacological activation/ inhibition of AMPK and the formation of AAA.

Experiment 1: Chemicals compounds and AAA progression.

To evaluate the relationship between AMPK activation and AAA formation, both AMPK activator and inhibitor were used. AICAR (5-aminoimidazole-4carboxamide-1- $\beta$-d-ribofuranoside) was used as AMPK activator and Compound $\mathrm{C}$ was used as AMPK inhibitor. Mice were divided into four groups ( $\mathrm{n}=18$ in each group), one group was used as normal control (Sham group). Rest AAA mice were randomly given AICAR (500 mg/ $\mathrm{kg}$, i.p. q.d. AAA+ACIAR group), Compound C (300 mg/ $\mathrm{kg}$, i.p. q.d. AAA + C. C group) or equal volume of PBS (Phosphate Buffer solution, AAA group). These injections were started once the implantation of pumps and persisted 28 days.

Experiment 2: Metformin and AAA progression

In the second in vivo study, mice were randomly divided into four groups ( $\mathrm{n}=18$ in each group). One group was used as normal control (Sham group) and another group was given metformin (Sham+MET group) at a dose of $100 \mathrm{mg} / \mathrm{kg} /$ day in normal drinking water. Rest two groups were inducted to aneurysm. Among them, one group was given normal drinking water (AAA group) and another group was given metformin (AAA+MET group).

\section{Histological analysis}

Mouse suprarenal aortas were fixed in $4 \%$ paraformaldehyde for at least 24 hours, paraffin- embedded, cut into 5- $\mu \mathrm{m}$ slices, and deparaffinized. HE staining, Elastic Van-Gieson (EVG) staining and masson-trichrome staining were performed by a standard protocol. Immunohistochemical (IHC) studies were performed following standard protocol using the antiCD68 (cluster of differentiation 68) antibody (Ab955, dilution rate: $1: 150$ ), anti-CD31 (platelet/endothelial cell adhesion molecule 1) antibody (Ab38364, dilution rate: 1:50), anti-alpha-smooth muscle actin ( $\alpha$-SMA) antibody (Ab5694, dilution rate: 1:200), anti-MMP-2 antibody (Ab 37150, dilution rate: 1:200) and anti-MMP-9 antibody (Ab 38898, dilution rate: 1:500) [47]. Pre-absorption tests were performed to polyclone antibodies (Ab5694, Ab 37150, Ab 38898). Smooth muscle actin (Thermo Fisher, A12375), Matrix Metalloproteinases-2 recombined protein (Thermo Fisher, RP-77542) and Matrix Metalloproteinases-9 recombined protein (Thermo Fisher, RP-75655) were used in the pre-absorption tests. After primary incubation, slices were washed and incubated with the appropriate secondary antibody and stained with 3, 3-diaminobenzidine.

Medial smooth muscle density was calculated by dividing the histological-positive area by the total area. Number of CD 68-positive macrophages CD31-positive microvessels were measured by counting the total number in 5 grid fields composed of a $400 \times 250-\mu \mathrm{m}$ rectangle $(0.1$ $\mathrm{mm}^{2}$ ) in each mouse.

\section{qRT-PCR (quantitative real-time reverse- transcription polymerase chain reaction)}

Total RNA was extracted from suprarenal aorta using Trizol Reagent (Invitrogen) according to the manufacturer's protocol. $1 \mu \mathrm{g}$ sample of total RNA of the aorta was reverse-transcribed to cDNA (complimentary DNA) with the Strand cDNA Synthesis Kit (Takara). qRT-PCR analysis was performed using the Power SYBR Green PCR Mastermix (Takara) according to the manufacturer's protocol. Primers used in the PCR were described in the Supplementary Table 1.

\section{Western blot}

Proteins were isolated from frozen suprarenal aortas using RIPA buffer (Beyotime Institute of Biotechnology, Shanghai, China) containing protease inhibitors. Protein extracts were separated by $10 \%$ sodium dodecyl sulfatepolyacrylamide gel electrophoresis and electrically transferred to polyvinylidene difluoride membranes, which were blocked with $10 \%$ nonfat dry milk in TBS- $0.05 \%$ Tween 20 for 1 hour. Then, membranes were incubated overnight at $4{ }^{\circ} \mathrm{C}$ using below primary antibodies: antiPhospho-AMPK $\alpha$ (Thr172) antibody (2535, cell signaling technology, 1:1000), anti-AMPK $\alpha$ antibody (2603, cell signaling technology, 1:1000), anti-Phospho-NF-кB P65 (nuclear factor $\kappa \mathrm{B}$ P65) (Ser536) antibody (3033, cell signaling technology, 1:1000), anti- NF-кB P65 antibody 
(4764, cell signaling technology, 1:1000), anti-Phospho -STAT3 (signal transducer and activator of transcription 3) (Tyr705) antibody (Ab76315, 1:20000), anti-STAT3 antibody (Ab119352, 1:1000), anti- $\beta$-actin antibody (sc81178, Santa Cruz Biotechnology, Santa Cruz, Calif, 1:500) and anti-GAPDH antibody (ab-8245, 1:5000). After that, the appropriate secondary antibody was applied. Blots were detected using an ECL Prime Western Blotting Detection reagent (Millipore). The signals were quantified by ImageJ software.

\section{Gelatin zymography}

Proteins were extracted from suprarenal aortas using RIPA buffer. Equal amounts of $10 \mu \mathrm{g}$ proteins were electrophoresed on $10 \%$ sodium dodecyl sulfatepolyacrylamide gel containing $0.1 \%$ gelatin. After that, the gels were renatured in renaturing buffer: $50 \mathrm{mM}$ Tris- $\mathrm{HCl}$ containing $100 \mathrm{mM} \mathrm{NaCl}$ and $2.5 \%$ Triton $\mathrm{X}-100$. Then, they were incubated with developing buffer, $50 \mathrm{mM}$ Tris$\mathrm{HCl}$ containing $10 \mathrm{mM} \mathrm{CaCl}_{2}$ overnight. After that, they were stained with staining buffer $(0.8 \%$ Brilliant Blue R) (Beyotime, Beijing, China), and distained in water. Band intensities were quantified by the use of ImageJ software.

\section{Statistical analyses}

Continuous data were presented as means \pm S.E.M. In comparisons of two treatment conditions, two-tailed Student $t$ test was used for normally distributed data and Mann-Whitney nonparametric test for skewed data that deviate from normality. In comparisons of three or more treatment conditions, one-way analysis of variance with Bonferroni post hoc test was used for normally distributed data and Kruskal-Wallis nonparametric test for skewed data. The semi-quantification for elastin and SMC content was compared using a nonparametric Kruskal-Wallis test, followed by post hoc analysis (Dunn test). $P<0.05$ was considered to be statistically significant. All data analyses were calculated by GraphPad Prism version 6 (GraphPad Software, Inc.).

\section{CONCLUSION}

Activation of AMPK signaling pathway inhibit in the Ang II-induced AAA formation in mice. Metformin may be a promising approach to the treatment of AAA.

\section{Abbreviations}

AMPK: AMP activated protein kinase

AAA: abdominal aortic aneurysm

AICAR: 5-aminoimidazole-4-carboxamide1- $\beta$-Dribofuranoside

MMP: matrix metalloproteinase

Ang: angiotensin
$\mathrm{NF}-\kappa \mathrm{B}$ : nuclear factor- $\kappa \mathrm{B}$

STAT-3: signal transducer and activator of transcription-3

IL: interleukin

MCP: macrophage chemotaxis protein

TNF: tumor necrosis factor

VEGF: vascular growth factors

$\mathrm{CD}$ : cluster of differentiation

Flt: fms related tyrosine kinase

EVG: elastic van gieson

HE: hematoxylin-eosin

SMA: smooth muscle actin

MET: metformin

HR: heart rate

BP: blood pressure

BM: body mass

IHC: immunohistological chemistry

WB: western blot

qRT-PCR: quantitative real-time reversetranscription polymerase chain reaction

\section{Author contributions}

L.Y., X.J. and XJ.W. designed the study. L.Y., G.L. and PX.G. performed the animal experiment. YX.H., H.Z., and MH.W. performed the IHC experiment. L.Y., L.S. and H.Y. analyzed the results. L.S. and XJ.W. wrote the paper. All authors discussed the results and commented on the manuscript.

\section{ACKNOWLEDGMENTS}

The authors would like to thank to Dr. Edward C. Mignot, Shandong University, for linguistic advice.

\section{CONFLICTS OF INTEREST}

We wish to confirm that there are no known conflicts of interest associated with this publication and there has been no significant financial support for this work that could have influenced its outcome.

\section{FUNDING}

This work was supported, in part, by the National Natural Science Foundation of China [grant number: 81470575, 8157020626, 81670435 and 81500375], National Natural Science Foundation of China and the Natural Science Foundation of Shandong Province [grant number: ZR2012HM063, ZR2015HQ001 and ZR2015PH064].

\section{REFERENCES}

1. Blomkalns AL, Gavrila D, Thomas M, Neltner BS, Blanco VM, Benjamin SB, McCormick ML, Stoll LL, Denning 
GM, Collins SP, Qin Z, Daugherty A, Cassis LA, et al. CD14 directs adventitial macrophage precursor recruitment: role in early abdominal aortic aneurysm formation. $\mathrm{J}$ Am Heart Assoc. 2013; 2:e00065.

2. Yang L, Shen L, Li G, Yuan H, Jin X, Wu X. Silencing of hypoxia inducible factor-1alpha gene attenuated angiotensin -induced abdominal aortic aneurysm in apolipoprotein E-deficient mice. Atherosclerosis. 2016; 252:40-49.

3. Baxter BT, Terrin MC, Dalman RL. Medical management of small abdominal aortic aneurysms. Circulation. 2008; 117:1883-1889.

4. Hardie DG, Carling D, Carlson M. The AMP-activated/ SNF1 protein kinase subfamily: metabolic sensors of the eukaryotic cell? Ann Rev Biochem. 1998; 67:821-855.

5. Stapleton D, Mitchelhill KI, Gao G, Widmer J, Michell BJ, Teh T, House CM, Fernandez CS, Cox T, Witters LA, Kemp BE. Mammalian AMP-activated protein kinase subfamily. J Biol Chem. 1996; 271:611-614.

6. Wu Y, Viana M, Thirumangalathu S, Loeken MR. AMPactivated protein kinase mediates effects of oxidative stress on embryo gene expression in a mouse model of diabetic embryopathy. Diabetologia. 2012; 55:245-254.

7. Inoki K, Kim J, Guan KL. AMPK and mTOR in cellular energy homeostasis and drug targets. Ann Rev Pharmacol Toxicol. 2012; 52:381-400.

8. Vasamsetti SB, Karnewar S, Kanugula AK, Thatipalli AR, Kumar JM, Kotamraju S. Metformin inhibits monocyte-tomacrophage differentiation via AMPK-mediated inhibition of STAT3 activation: potential role in atherosclerosis. Diabetes. 2015; 64:2028-2041.

9. Cao Q, Cui X, Wu R, Zha L, Wang X, Parks JS, Yu L, Shi $\mathrm{H}$, Xue B. Myeloid deletion of alpha1AMPK exacerbates atherosclerosis in LDL receptor knockout (LDLRKO) mice. Diabetes. 2016; 65:1565-1576.

10. Ding Y, Zhang M, Zhang W, Lu Q, Cai Z, Song P, Okon IS, Xiao L, Zou MH. AMP-activated protein kinase alpha 2 deletion induces VSMC phenotypic switching and reduces features of atherosclerotic plaque stability. Circ Research. 2016; 119:718-730.

11. Wang S, Zhang C, Zhang M, Liang B, Zhu H, Lee J, Viollet B, Xia L, Zhang Y, Zou MH. Activation of AMP-activated protein kinase alpha2 by nicotine instigates formation of abdominal aortic aneurysms in mice in vivo. Nat Med. 2012; 18:902-910.

12. Daugherty A, Cassis LA. Mouse models of abdominal aortic aneurysms. Arterioscler Thromb Vasc Biol. 2004; 24:429-434.

13. Foretz M, Guigas B, Bertrand L, Pollak M, Viollet B. Metformin: from mechanisms of action to therapies. Cell Metabol. 2014; 20:953-966.

14. Cai Z, Ding Y, Zhang M, Lu Q, Wu S, Zhu H, Song P, Zou MH. Ablation of adenosine monophosphate-activated protein kinase alpha1 in vascular smooth muscle cells promotes diet-induced atherosclerotic calcification in vivo. Circ Res. 2016; 119:422-433.

15. Scott JW, van Denderen BJ, Jorgensen SB, Honeyman JE, Steinberg GR, Oakhill JS, Iseli TJ, Koay A, Gooley PR, Stapleton D, Kemp BE. Thienopyridone drugs are selective activators of AMP-activated protein kinase beta1-containing complexes. Chem Biol. 2008; 15:1220-1230.

16. Martin H, Burgess EJ, Smith WA, McGhie TK, Cooney JM, Lunken RC, de Guzman E, Trower T, Perry NB. JAK2 and AMP-kinase inhibition in vitro by food extracts, fractions and purified phytochemicals. Food Funct. 2015; 6:305-312.

17. Lanner JT, Georgiou DK, Dagnino-Acosta A, Ainbinder A, Cheng Q, Joshi AD, Chen Z, Yarotskyy V, Oakes JM, Lee CS, Monroe TO, Santillan A, Dong K, et al. AICAR prevents heat-induced sudden death in RyR1 mutant mice independent of AMPK activation. Nat Med. 2012; 18:244-251.

18. Zheng T, Yang X, Wu D, Xing S, Bian F, Li W, Chi J, Bai X, Wu G, Chen X, Zhang Y, Jin S. Salidroside ameliorates insulin resistance through activation of a mitochondriaassociated AMPK/PI3K/Akt/GSK3beta pathway. Br J Pharmacol. 2015; 172:3284-3301.

19. Saldivia M, Ceballos-Perez G, Bart JM, Navarro M. The AMPK $\alpha 1$ pathway positively regulates the developmental transition from proliferation to quiescence in trypanosoma brucei. Cell Rep. 2016; 17:660-670.

20. Liu X, Chhipa RR, Nakano I, Dasgupta B. The AMPK inhibitor compound $\mathrm{C}$ is a potent AMPK-independent antiglioma agent. Mol Cancer Ther. 2014; 13:596-605.

21. Namgaladze D, Kemmerer $M$, von Knethen A, Brune B. AICAR inhibits PPARgamma during monocyte differentiation to attenuate inflammatory responses to atherogenic lipids. Cardiovasc Res. 2013; 98:479-487.

22. Bradley EA, Eringa EC, Stehouwer CD, Korstjens I, van Nieuw Amerongen GP, Musters R, Sipkema P, Clark MG, Rattigan S. Activation of AMP-activated protein kinase by 5-aminoimidazole-4-carboxamide-1-beta-D-ribofuranoside in the muscle microcirculation increases nitric oxide synthesis and microvascular perfusion. Arterioscler Thromb Vasc Biol. 2010; 30:1137-1142.

23. Daugherty A, Powell JT. Recent highlights of ATVB: aneurysms. Arterioscler Thromb Vasc Biol. 2014; 34:691-694.

24. Miyama N, Dua MM, Yeung JJ, Schultz GM, Asagami T, Sho E, Sho M, Dalman RL. Hyperglycemia limits experimental aortic aneurysm progression. J Vasc Surg. 2010; 52:975-983.

25. Kaneko H, Anzai T, Takahashi T, Kohno T, Shimoda M, Sasaki A, Shimizu H, Nagai T, Maekawa Y, Yoshimura K, Aoki H, Yoshikawa T, Okada Y, et al. Role of vascular 
endothelial growth factor-A in development of abdominal aortic aneurysm. Cardiovasc Res. 2011; 91:358-367.

26. Watanabe A, Ichiki T, Sankoda C, Takahara Y, Ikeda J, Inoue E, Tokunou T, Kitamoto S, Sunagawa K. Suppression of abdominal aortic aneurysm formation by inhibition of prolyl hydroxylase domain protein through attenuation of inflammation and extracellular matrix disruption. Clin Sci. 2014; 126:671-678.

27. Zhu C, Xiong Z, Chen X, Lu Z, Zhou G, Wang D, Bao J, $\mathrm{Hu} \mathrm{X}$. Soluble vascular endothelial growth factor (VEGF) receptor-1 inhibits migration of human monocytic THP-1 cells in response to VEGF. Inflamm Res. 2011; 60:769-774.

28. Zhao Q, Ishibashi M, Hiasa K, Tan C, Takeshita A, Egashira K. Essential role of vascular endothelial growth factor in angiotensin II-induced vascular inflammation and remodeling. Hypertension. 2004; 44:264-270.

29. Tsai KL, Hung CH, Chan SH, Shih JY, Cheng YH, Tsai YJ, Lin HC, Chu PM. Baicalein protects against oxLDLcaused oxidative stress and inflammation by modulation of AMPK- alpha. Oncotarget. 2016; 7:72458-72468. https:// doi.org/10.18632/oncotarget.12788.

30. Li C, Ding XY, Xiang DM, Xu J, Huang XL, Hou FF, Zhou QG. Enhanced M1 and Impaired M2 Macrophage Polarization and Reduced Mitochondrial Biogenesis via Inhibition of AMP Kinase in Chronic Kidney Disease. Cell Physiol Biochem. 2015; 36:358-372.

31. Pilon G, Dallaire P, Marette A. Inhibition of inducible nitricoxide synthase by activators of AMP-activated protein kinase: a new mechanism of action of insulin-sensitizing drugs. J Biol Chem. 2004; 279:20767-20774.

32. Sag D, Carling D, Stout RD, Suttles J. Adenosine 5'-monophosphate-activated protein kinase promotes macrophage polarization to an anti-inflammatory functional phenotype. J Immunology. 2008; 181:8633-8641.

33. Yang Z, Kahn BB, Shi H, Xue BZ. Macrophage alpha1 AMP-activated protein kinase (alpha1AMPK) antagonizes fatty acid-induced inflammation through SIRT1. J Biol Chem. 2010; 285:19051-19059.

34. Longo GM, Xiong W, Greiner TC, Zhao Y, Fiotti N, Baxter BT. Matrix metalloproteinases 2 and 9 work in concert to produce aortic aneurysms. J Clin Invest. 2002; 110:625-632.

35. Qin Z, Bagley J, Sukhova G, Baur WE, Park HJ, Beasley D, Libby P, Zhang Y, Galper JB. Angiotensin II-induced TLR4 mediated abdominal aortic aneurysm in apolipoprotein $\mathrm{E}$ knockout mice is dependent on STAT3. J Mol Cell Cardiol. 2015; 87:160-170.

36. Nakashima H, Aoki M, Miyake T, Kawasaki T, Iwai M, Jo N, Oishi M, Kataoka K, Ohgi S, Ogihara T, Kaneda Y, Morishita R. Inhibition of experimental abdominal aortic aneurysm in the rat by use of decoy oligodeoxynucleotides suppressing activity of nuclear factor kappaB and ets transcription factors. Circulation. 2004; 109:132-138.

37. Kaneko H, Anzai T, Morisawa M, Kohno T, Nagai T, Anzai A, Takahashi T, Shimoda M, Sasaki A, Maekawa
Y, Yoshimura K, Aoki H, Tsubota K, et al. Resveratrol prevents the development of abdominal aortic aneurysm through attenuation of inflammation, oxidative stress, and neovascularization. Atherosclerosis. 2011; 217:350-357.

38. Cerezo M, Tichet M, Abbe P, Ohanna M, Lehraiki A, Rouaud F, Allegra M, Giacchero D, Bahadoran P, Bertolotto C, Tartare-Deckert S, Ballotti R, Rocchi S. Metformin blocks melanoma invasion and metastasis development in AMPK/p53-dependent manner. Mol Cancer Thera. 2013; 12:1605-1615.

39. Martin-Montalvo A, Mercken EM, Mitchell SJ, Palacios HH, Mote PL, Scheibye-Knudsen M, Gomes AP, Ward TM, Minor RK, Blouin MJ, Schwab M, Pollak M, Zhang Y, et al. Metformin improves healthspan and lifespan in mice. Nat Commun. 2013; 4:2192.

40. Fujimura N, Xiong J, Kettler EB, Xuan H, Glover KJ, Mell MW, Xu B, Dalman RL. Metformin treatment status and abdominal aortic aneurysm disease progression. J Vasc Surg. 2016; 64:46-54 e48.

41. Boss M, Newbatt Y, Gupta S, Collins I, Brune B, Namgaladze D. AMPK-independent inhibition of human macrophage ER stress response by AICAR. Sci Rep. 2016; 6:32111.

42. Rao E, Zhang Y, Li Q, Hao J, Egilmez NK, Suttles J, Li B. AMPK-dependent and independent effects of AICAR and compound $\mathrm{C}$ on T-cell responses. Oncotarget. 2016; 7:33783-33795. https://doi.org/10.18632/oncotarget.9277.

43. Feng Y, Wang S, Zhang Y, Xiao H. Metformin attenuates renal fibrosis in both AMPKalpha2-dependent and independent manners. Clin Exp Pharmacol Physiol. 2017; 44:648-655.

44. Milewicz DM, Trybus KM, Guo DC, Sweeney HL, Regalado E, Kamm K, Stull JT. Altered smooth muscle cell Force Generation as a Driver of Thoracic Aortic Aneurysms and Dissections. Arterioscler Thromb Vasc Biol. 2017; 37:26-34.

45. Wang J, Lindholt JS, Sukhova GK, Shi MA, Xia M, Chen H, Xiang M, He A, Wang Y, Xiong N, Libby P, Wang JA, Shi GP. IgE actions on CD4 $+\mathrm{T}$ cells, mast cells, and macrophages participate in the pathogenesis of experimental abdominal aortic aneurysms. EMBO Mol Med. 2014; 6:952-969.

46. Folkesson M, Vorkapic E, Gulbins E, Japtok L, Kleuser B, Welander M, Lanne T, Wagsater D. Inflammatory cells, ceramides, and expression of proteases in perivascular adipose tissue adjacent to human abdominal aortic aneurysms. J Vasc Surg. 2017; 65:1171-1179.

47. Kong X, Yuan H, Wu X, Zhang J, Zhou H, Wang M, Liu $\mathrm{Y}$, Jin X. High-mobility-group box protein 1A box reduces development of sodium laurate-induced thromboangiitis obliterans in rats. J Vasc Surg. 2013; 57:194-204. 